\title{
The use of multisimulation in determining fire hazards in buildings covered by expertise
}

\author{
Przemysław Kubica ${ }^{1}$, and Tomasz Wdowiak ${ }^{1, *}$ \\ ${ }^{1}$ The Main School of Fire Service, Faculty of Fire Safety Engineering, 52/54 Slowackiego St., 01-629 \\ Warsaw, Poland
}

\begin{abstract}
The variety of architectural solutions of buildings and the multitude of purposes to which they will be used enforces the use of solutions not directly provided for in the law. To ensure an adequate level of safety are used replacement and substitution conditions. The currently functioning system of expert opinions is based on expert knowledge, which is often difficult to assess and gives divergent solutions for similar cases. Development of an objective and repeatable method of matching optimal solutions to the threat of fire is an area of current research in the field of fire safety engineering. The subject of the work covered the process of determining the scenarios causing the greatest threat while estimating the probability of its appearance. Using the multisimulation method - multiple simulations for a given object with determine variables is established the probability distribution of specific negative events. Variables are drawn based on distributions developed with statistical methods from historical data. The method is based on the known input data - British Standards and with keeping a sufficiently large number of draws gives reproducible results - probability distributions. In addition, the model can be expanded with new variables and adapted to atypical issues.
\end{abstract}

\section{Introduction}

The variety of architectural solutions of buildings and the multitude of purposes to which they will be used enforces the use of solutions ensuring safety not directly provided in the law. Taking into account the possibility of changing the regulations, the purpose of the building's use or its rebuilding, it increases the diversity several times. It is not possible to predict, by any legal system, sufficiently detailed regulations ensuring, in given circumstances, an appropriate and economically justified level of safety for building users. For this reason, the legislator, by creating regulations, set general rules that should be met by buildings. These rules, due to their general nature, allow their use in most cases. At the same time, the possibility of derogating from these principles was provided after fulfilling certain conditions [1]. One of such conditions is to ensure comparable safety conditions. It is not by coincidence that conditions are comparable and not the same. This is due to the fact that no two solutions are able to give the same results, taking into account the random nature of the risks associated with the creation and development of a fire. It is therefore

\footnotetext{
* Corresponding author: tomasz.wdowiak.sgsp@gmail.com
} 
necessary to evaluate the proposed solution to replace the originally provided for in the regulations. This process takes place in two stages. The first stage is the creation of an expert opinion, which proposes a suitable solution at the same time justifying them. The second stage is approval by the appropriate authority, this is the local headquarters of the State Fire Service. The weakness of this system is the subjectivity of selection and evaluation of such a solution. In connection with the above, there is a need for objective safety measurement related to the proposed and original solution. In the further part of the study, the authors presented proposals for assessing the safety level of a building in which one of the most popular replacement solutions is used.

\section{Fire alarm system}

One of the most frequently used replacement solutions is the fire alarm system (FAS). It can be used in this role is possible if the building is not in the list of buildings obligatorily equipped with this system. There are many advantages to finding a fire in its early phase. The first of these is the possibility of attempting to extinguish a fire with extinguishers or hydrants. The next is the possibility to start the evacuation in conditions when there are no smoke on the escape routes, and thus the evacuation conditions will not exceed one of the following levels [1]:

- the critical air temperature at the designed horizontal escape route at a height less than or equal to $1.8 \mathrm{~m}$ from the floor cannot exceed $60^{\circ} \mathrm{C}$,

- thermal radiation in the evacuation route not greater than $2.5 \mathrm{~kW} / \mathrm{m}^{2}$ for the exposure time longer than $30 \mathrm{~s}$,

- the range of visibility on the evacuation route at a height less than or equal to $1.8 \mathrm{~m}$ from the floor less than $10 \mathrm{~m}$ (for signs illuminated at least $20 \mathrm{~m}$ ),

- temperature of hot fire gases at a height of over $2.5 \mathrm{~m}$ from the level of the escape route above $200^{\circ} \mathrm{C}$,

- oxygen content below $15 \%$.

Another advantage is the early notification of the fire brigade and limiting the effects of fire as a result of an early fire-fighting operation. The qualitative impact of using FAS on the level of fire safety seems to be easy to see and its potential benefits can be multiplied. It is more problematic to express in figures the improvement of fire safety after application FAS. Attempts at this approach are found in British Standards. Due to its universal nature and the taking a margin of safety, this approach is simplified but meets the need to express safety in numbers. An example of such an approach is in tabel 1, the proposed time of reaction of users of different types of building to fire and start evacuation.

Table 1. Proposed time of reaction of users of different types of building to fire and start evacuation [own work, based on $[2,3]]$.

\begin{tabular}{|l|l|l|}
\hline $\begin{array}{l}\text { Scenario category and possible } \\
\text { modifications }\end{array}$ & $\begin{array}{l}\text { First users [min] } \\
\boldsymbol{\Delta} \mathbf{t}_{\text {reaction(first) }}\end{array}$ & $\begin{array}{l}\text { Last users [min] } \\
\boldsymbol{\Delta} \mathbf{t}_{\text {reaction(last }}\end{array}$ \\
\hline A: awake and familiar & 0.5 & 1 \\
\hline M1 B1-B2 A1-A2 & 1 & 2 \\
\hline M2 B1-B2 A1-A2 & $>15$ & $>15$ \\
\hline M3 B1-B2 A1-A3 & \multicolumn{2}{|l|}{} \\
\hline $\begin{array}{l}\text { For B3, add 0.5 to find a way. } \\
\text { M1 requires a Voice Alarm } \\
\text { System (VAS) }\end{array}$ & \\
\hline B: awake and unfamiliar & 0.5 & 2 \\
\hline M1 B1 A1-A2 & 1 & $>15$ \\
\hline M2 B1 A1-A2 & $>15$ & \\
\hline M3 B1 A1-A3 &
\end{tabular}


Where:

\begin{tabular}{|l|l|l|}
\hline $\begin{array}{l}\text { Scenario category and possible } \\
\text { modifications }\end{array}$ & $\begin{array}{l}\text { First users [min] } \\
\Delta \mathbf{t}_{\text {reaction(first) }}\end{array}$ & $\begin{array}{l}\text { Last users [min] } \\
\boldsymbol{\Delta} \mathbf{t}_{\text {reaction(last }}\end{array}$ \\
\hline $\begin{array}{l}\text { For B2, add 0.5 to find a way. } \\
\text { For B3, add 1 to find a way. M1 } \\
\text { requires a VAS }\end{array}$ & \multicolumn{2}{|l|}{} \\
\hline D: medical care & \multicolumn{3}{|l|}{} \\
\hline awake and unfamiliar (e.g. day care, clinic, dental office) \\
\hline M1 B1 A1-A2 & 0.5 & 2 \\
\hline M2 B1 A1-A2 & 1 & 3 \\
\hline M3 B1 A1-A3 & $>15$ & $>15$ \\
\hline $\begin{array}{l}\text { For B2, add 0.5 to find a way. } \\
\text { For B3, add 1 to find a way. M1 } \\
\text { requires a VAS }\end{array}$ & \multicolumn{2}{|l}{} \\
\hline E: transport & \multicolumn{2}{|l}{} \\
\hline awake and unfamiliar (e.g. railway and bus stations, airport terminals) \\
\hline M1 B3 A1-A2 & 1.5 & 4 \\
\hline M2 B3 A1-A2 & 2 & 5 \\
\hline M3 B3 A1-A3 & $>15$ & $>15$ \\
\hline M1 i M2 requires a VAS & \multicolumn{2}{|l}{} \\
\hline
\end{tabular}

Alarming time:

- A1 - building equipped with FAS with one-stage alarming, then alarming time $0 \mathrm{~s}$.

- A2 - building equipped with FAS with two-stage alarming, then alarming time set in fire alarm control panel.

- A3 - building equipped with manual alarming system, then alarming time is difficult to determine.

The level of complexity of the building:

- B1 (a simple supermarket) - simple regular shape, single-story, with one or several rooms,

- B2 (simple multi-story) - simple building, many rooms, with a clear communication system,

- B3 - a large, complex building, a complex of connected buildings, e.g. shopping centers.

Management system:

- M1 - users and staff well trained, regular fire and evacuation exercises, a high level of fire protection, FAS and VAS.

- M2 - slightly worse than M1, possible lack of external audits, lack of service on each floor, FAS.

- M3 - standard equipment and training of employees (minimum, acceptable), a possible manual alarming system.

The values given above may be one of the variables that will be used to calculate the value of the level of safety. The problems that arise here are the arbitrariness of the given values or the accepting only one (minimum) end of the range. The first one raises the question whether in all cases this value has a real reflection and whether it should be increased or taken it multiples for security purposes. The second problem is to choose the right value from the given range. At the same time, it may raise natural doubt that the minimum value will be considered too optimistic and not objective [4]. The next issue is the adoption of values characterizing the level of risk. There are at least several possible solutions: individual probability of death and/or severe injury, evacuation time, risk profile for fatalities and/or severe injuries, time to achieve certain parameters by fire. Each of them must in this case be calculated separately on the basis of the values assumed by the calculator. Therefore, it is a method that already quantifies the level of safety, but in the opinion of the authors insufficient to comprehensively determine the correctness of the choice of replacement or substitute solutions. 


\section{Multisimulations}

A comprehensive method of quantifying fire safety is to determine the risk value by multisimulation. The proposed method of fire risk assessment is based on the execution of many simulations of the fire development in the building. In this case was used the aamks, platform provided by the Main School of Fire Service. The platform has many sub-models that generate and process data. To simulate the fire development, is used the CFAST zone model, and for evacuation, the proprietary model of velocity vectors of evacuees. By exchanging, among other things, such data as the location of the fire, its power and course, as well as the number of people in the rooms and their setting in relation to architecture and even equipment, it cans get close to an infinite number of scenarios. Using the methodology of generation of individual variables by the Monte Carlo method based on distributions created on the basis of research and historical data, histograms showing the most probable fire courses can be obtained [5]. At the same time, it cans quickly find scenarios that generate the greatest threats to life, health and causing the greatest damage. An illustration of the operation of multisimulation is presented by an assessment of the impact of FAS on the level of safety on the example of an educational building in which the length of an evacuation approach is exceeded.

In the analyzed object, the length of the evacuation access is $32 \mathrm{~m}$ (fig. 1.). The requirements of the regulations is a length not exceeding $20 \mathrm{~m}$.

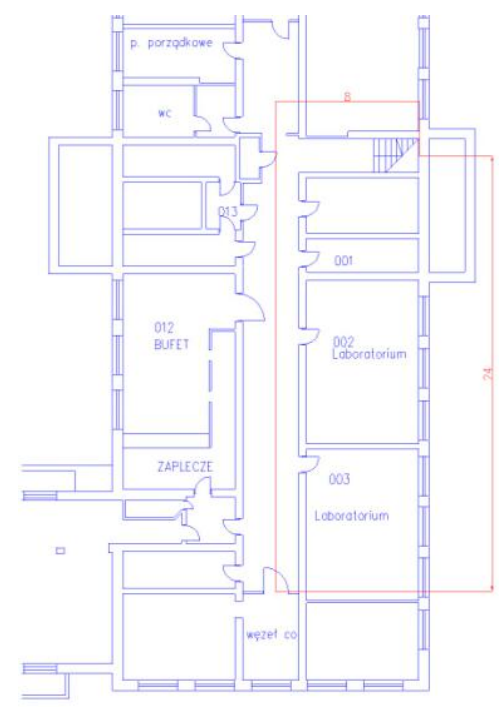

Fig. 1. Founder of the analyzed building [own work, based on building documentation].

Fire risk was analyzed for three cases:

1) current status,

2) rebuilding and bringing evacuation access compliance with regulations,

3) current status + FAS.

In the first two cases it was assumed that alarming about the fire will occur after the users of the facility have noticed signs of fires. So a fire will break out in a room where people are staying, or signs of a fire will reach rooms in which there is a person. According to the idea of multisimulation, the layout of people in rooms and the location of a fire place are selected randomly based on statistical data. In the third case, alarming occurs after detecting a fire by the detector and the time delay associated with confirming the fire according to the two-stage ordinary alarm, the value of which is random. Figure 2 shows 
the visualizations of the course of exemplary scenarios, place of the fire is indicated by a large yellow-red dot, and users by small dots. The color of the user's dots changes with increasing fire exposure, from light green to red meaning death.
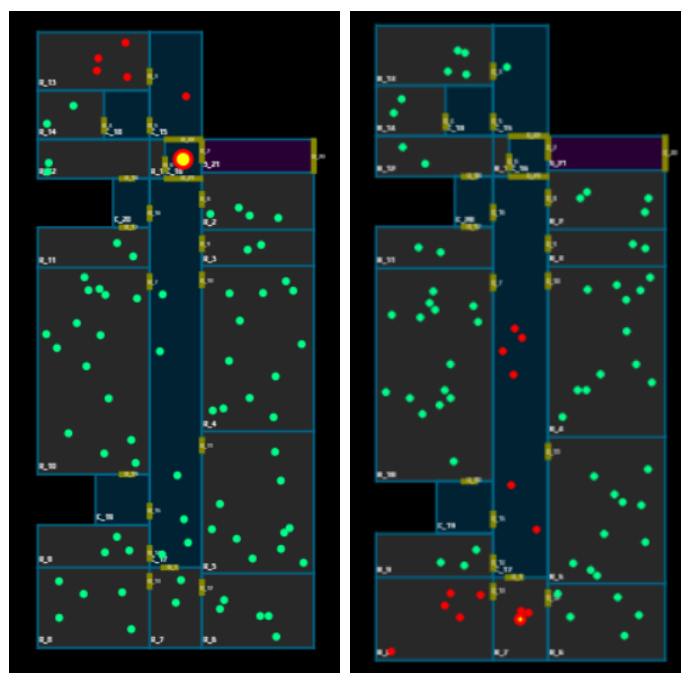

Fig. 2. Fire on escape route, potential fatalities because of fire (left), very fast spreading fire on escape route potential fatalities because of fire and heat (right) [own work].

According to the assumptions of the model, which is based on [BS], the lack of FAS causes a significant delay during the commencement of evacuation. In addition, in the case of an unfavorable location of a fire: a fire on an escape route, a fire in rooms near the confluence of escape routes, a very rapid development of a fire or a large amount of smoke generates a high probability of fatalities. A significant number of evacuation cases took place in the smoky conditions of the evacuation route (e.g. a fire noticed after the door was blown into the escape route or a fire with a large generation of smoke through the left open door during evacuation from the fire-affected room).
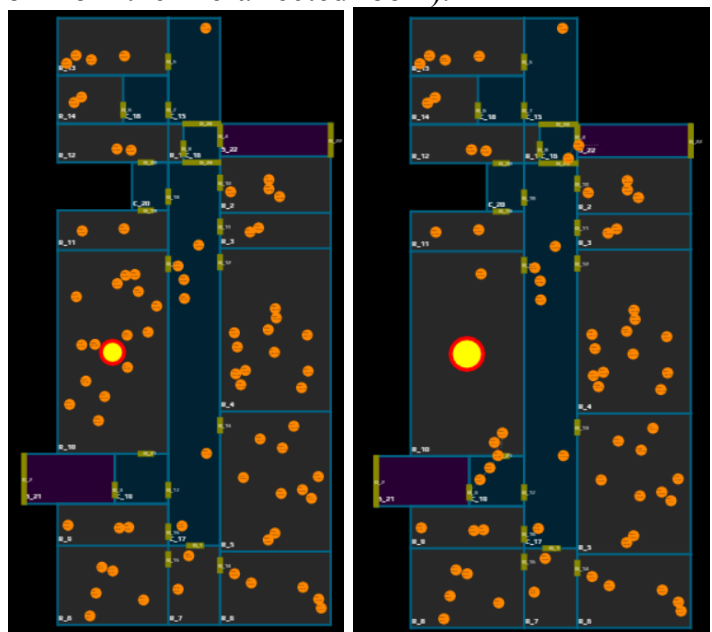

Fig. 3. Additional staircase on start of fire (left), star of evacuation from room with fire in two directions (right) [own work]. 
The second analyzed case was to bring the state of the building to the requirements of the law, it is rebuilding ensuring evacuation to another part of the building that is a separate fire zone by a second staircase. After applying this solution, the time of evacuation is shortened, among others due to the smaller load on each of the evacuation routes, as well as the probability of evacuation by an evacuation route which is not smoky. Thus, the likelihood of fatalities or serious injuries is reduced. However, it should be remembered that this case has no effect on the time of fire detection, and thus the time to start the evacuation alarm, which further depends on alarming by people who have noticed the symptoms of fire and have taken action to inform other users. Figure 3 shows the course of one of the scenarios for two staircases, showing the evacuation route with two evacuation directions.
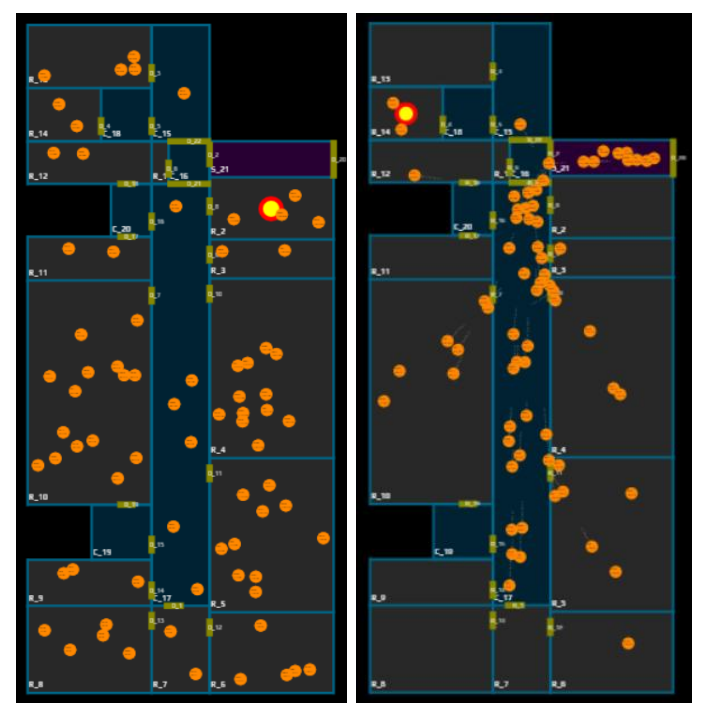

Fig. 4. Current status - evacuation only room with fire (left), FAS - evacuation of all floor (right) [own work].

The use of the fire alarm system already affects the time of the evacuation start, increasing the chance of evacuation in the conditions of a non-smoky and non-hazardous evacuation route, thus shortening the evacuation time itself. This translates into a reduction in the likelihood of fatalities. Figure 4 presents a comparison of evacuation scenario. In the first variant without FAS, when people from the fire compartment are first evacuated. In the second case, the evacuation takes place simultaneously on the entire story due to alarming by the FAS. Currently, the fire development model used in multisimulations does not take into account the probability of attempting to extinguish a fire in the early phase as well as the consequences of this action (extinguishing or delaying the development of a fire). The aspect raised by the authors is also the failure to take into account the earlier start of the rescue and firefighting operation by the fire brigade advised by the FAS. At the same time, it should be noted that there are far-reaching actions in this topic aimed at implementing this variable to the model.

\section{Results and discussion}

Based on the analysis, it was found: The level of safety of the current state is presented in the form of a risk profile according to the figure 5 . 

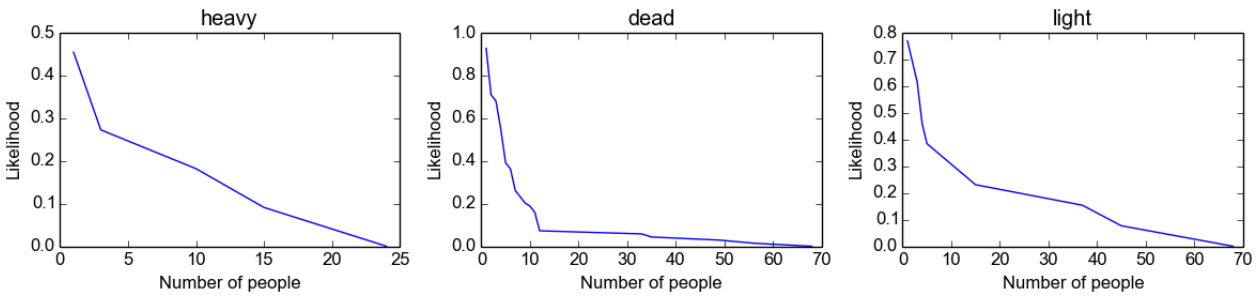

Fig. 5. Current status - risk profile [own work].

It can be classified as medium risk.

Reconstruction and adaptation to the requirements of the regulations reduces the risk according to fig.


Fig. 6. Additional staircase - risk profile [own work].

With regard to the previous risk, the risk is lower, but still in the medium group.

The use of FAS results in increased security as shown in the figure and risk classification as low.
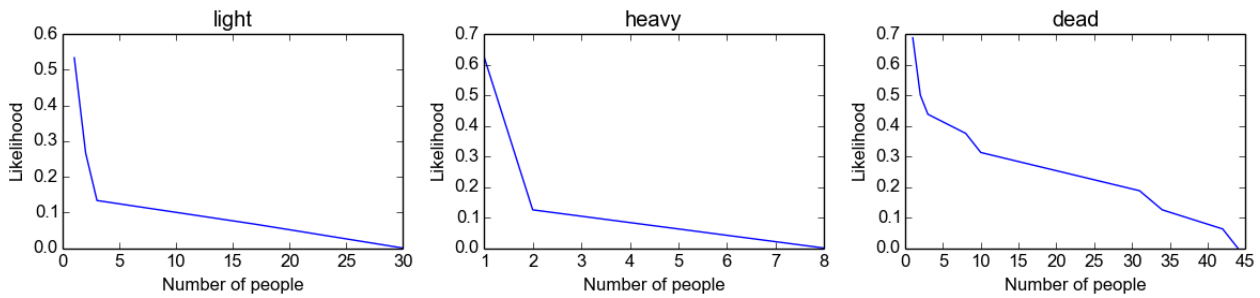

Fig. 7. FAS - risk profile [own work].

The above analysis confirmed the rationality and completeness of using FAS as a replacement solution in the event of non-compliance with the requirements of the law on the fire safety of buildings. Additives determined the magnitude of this impact using numerical values, using a repetitive method. The application of the risk analysis method based on quantitative methods gives the opportunity to measure and compare the adopted solutions, and thus to make them acceptable. The risk assessment based on multisimulations enables an objective assessment of the building's fire safety. It allows for the generation of various quantity that can be used to compare safety (figure 8) [6]. 

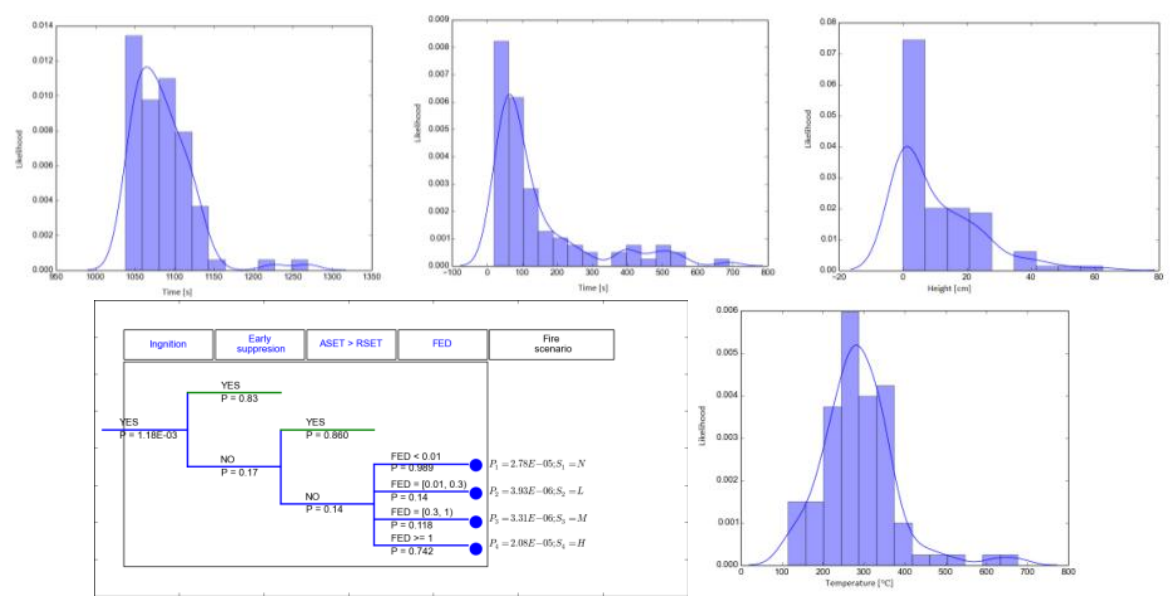

Fig. 8. Quantity that can be used to compare safety: RSET - Required Safe Egress Time (left up ), ASET - Available Safe Egress Time (middle up), height of smoke layer (right up), risk tree showing possible variants of scenarios determining the probability of each of them and taking into account the individual probability of death (left down ), temperature of smoke layer (right down ), [own work].

Consequently, it provides the basis for comparing design concepts and identifying those that provide an acceptable level of safety. This is an important tool in the design of buildings based on goals to achieve, not on the rigid compliance with the requirements of the regulations.

\section{References}

1. Regulation of the Minister of Infrastructure of 12 April 2002. regarding technical conditions, which should be met by buildings and their location (Consolidated text: Dziennik Ustaw 2015, item 1422, with subsequent amendments)

2. G. Dzień, M. Pecio, K. Łącki, Ochrona Przeciwpożarowa 3, 4 (2015)

3. PD 7974-6:2004, The application of the safety engineering principles to fire safety design of building. Human factors. Life safety strategies. Occupant evacuation, behavior and condition (Sub-system 6).

4. BS 9999:2008 Code if practice for fire safety in the design, management and use of building.

5. A. Krasuski, K. Kreński, A-Evac: the evacuation simulator for stochastic environment, arXiv preprint arXiv:1711.09229, (2017)

6. https://aamks.inf.sgsp.edu.pl (28.09.2018) 